\title{
Entre cielo y tierra: la ligazón y el abismo en el Convivio
}

\author{
Juan Varela-Portas de Orduña \\ Universidad Complutense de Madrid \\ jivarelaportas@filol.ucm.es
}

\section{Resumen}

Este artículo repasa las ideas principales del Convivio de Dante interpretándolas como muestra de una crisis histórica de desacralización provocada por la difusión del modo de producción mercantil, que se traduce en una crisis intelectual en la que el autor trata de reformular el vínculo que une al Cielo y la Tierra, es decir, la matriz misma del inconsciente ideológico sacralizado feudal. Para ello, Dante recorre el proceso de creación-generación del mundo, por una parte, y el proceso de conocimiento que remonta al ser humano hasta la Sabiduría celeste. Dante trata así, infructuosamente, de crear una "sacralización civil» o «sacralización mercantil», sin lo cual, en todo caso, no será posible la escritura futura de la Commedia.

Palabras clave: Convivio; Filosofía; sacralización; nobleza de alma; orden civil.

\begin{abstract}
This article goes through the main ideas in Dante's Convivio interpreting them as a sample of a historical desacralization crisis caused by the spreading of the commercial production mode, which translates into an intellectual crisis where the author tries to reformulate the link binding Heaven with Earth, meaning the matrix itself of feudal sacralised ideological unconsciousness. To do so, Dante goes through the process of creation-generation of the World, on the one hand; and the process of knowledge, taking mankind to heavenly Wisdom. In doing this, Dante unsuccessfully attempts to create a 'civil sacralisation' or a 'commercial sacralisation'. Without this, in any case, he wouldn't have been able to later write the Commedia.
\end{abstract}

Keywords: Convivio; Philosophy; sacralisation; nobility of the soul; civil order. 
Intentaremos en las próximas páginas ${ }^{1}$ mostrar en qué sentido el Convivio es consecuencia de lo que podemos denominar la gran crisis de lectura, o primera crisis de desacralización, que, como resultado del impacto continuado de las relaciones mercantiles, desestabiliza el inconsciente ideológico sacralizado feudal, ${ }^{2}$ haciendo que las nociones, los comportamientos, los textos, etc., radicados en él no se sientan ya como plenamente válidos, sin que hayan surgido y se hayan consolidado otros útiles ya para el mantenimiento de una nueva organización socioeconómica. Uso, pues, el término "crisis» en su acepción gramsciana: ¿cómo explicar un mundo del que resulta evidente que no se ajusta a nuestra imagen de él, si aún no somos capaces de pensar desde fuera de esa imagen construida y constructora? Se dará entonces un intento de reelaborar las viejas nociones, retorcerlas, revisarlas, resituarlas, con la esperanza de que así podamos aplacar nuestra desazón y nuestra desorientación, sin percatarnos de que lo único que estamos consiguiendo es sacar más aún a la luz sus intrínsecas y medulares contradicciones internas, y su siempre latente desajuste con las "condiciones reales de existencia".

Como es sabido, el inconsciente ideológico sacralizado feudal — también llamado organicista-, se desarrolla a partir de la idea de que el mundo es una huella de Dios, una teofanía, que mantiene con el mundo supralunar divino una relación de semejanza-desemejanza, y establece por tanto con él un vínculo sustancial que es, al mismo tiempo, ligazón y abismo: es lo que en aquel horizonte ideológico sacralizado, en el que las contradicciones se tematizaban como «misterios», se denominaba «el misterio de la encarnación». Sin duda, el texto más hermoso y más preciso que describe esta concepción es la explicación del orden del universo que Beatriz le da a Dante cuando este inicia su ascensión astral, en el primero del Paradiso (I, 103-142).

Todas las cosas - comienza Beatriz — tienen entre ellas un orden (es decir, una jerarquía), y este orden es la forma (en sentido técnico escolástico, como iremos viendo) que hace que el universo sea semejante a Dios (v. 103-105), o, en otras palabras, el universo es un orden que reproduce por semejanza

1. Este trabajo es la ampliación y matización de las cuestiones que tratamos en el apartado dedicado al Convivio de nuestro libro de 2006 (Juan Varela-Portas, Dante Alighieri, Madrid: Síntesis, 2006, p. 94-105). Para mantener el rigor argumental hemos tenido que incluir en la parte final de este texto algunos párrafos de dicho libro (en concreto de las páginas 101-105).

2. Tomamos de Juan Carlos Rodríguez el concepto, de raigambre gramsciana y althusseriana, de inconsciente ideológico. Una síntesis explicativa de este concepto puede encontrarse en Juan Carlos Rogríguez, Tras la muerte del aura (en contra y a favor de la Ilustración), Granada: Universidad de Granada, 2011, p. 28-32, pero si se quiere entender con más profundizar deben leerse, entre otros textos de este autor, Juan Carlos Rodríguez, «La crítica en el boudoir», en ID., La norma literaria. Ensayos de crítica, Granada: Diputación provincial de Granada, 1984, p. 8-28 ( hay edición corregida y aumentada en Madrid: Debate, 2001), «Lecciones de escritura» y «Retorno para volver a empezar», en ID., De qué hablamos cuando hablamos de literatura, Granada: Comares, 2002, p. 21-58 y 639-656, y, por supuesto, su clásico Teoría e historia de la producción ideológica. Las primeras literaturas burguesas, Madrid: Akal, 1990. 
la esencia divina. En este orden, las criaturas racionales (ángeles y hombres: "le alte creature») ven la horma (el sello, la huella, el vestigio) del propio Dios («l'etterno valore»), el cual es el fin al que se ajusta el mencionado orden universal («la toccata norma») (v. 106-108). Por ello, en este orden, todas las naturalezas sienten una inclinación hacia su principio, Dios (v. 109-111) — diferente según se asemejen más o menos a Él (v. 110-111)—, por lo que se mueven por el gran mar del ser hacia diversos puertos, cada una movida por un instinto que le ha sido dado (v. 112-114), el que lleva el fuego hacia arriba (v. 115), el que hace que se mueva el corazón de los seres vivos (v. 116), el que mantiene unida y compacta la tierra (v. 117), y el que, en suma, también impulsa (como el arco a la flecha, v. 119) a las criaturas que tienen intelecto y amor (v. 118-120).

Precisemos algunas nociones básicas del discurso de Beatriz. En primer lugar, cuando usa las palabras "cosa» o «natura» para referirse a cualquier ser - vivo o no vivo: desde una piedra hasta los hombres - , lo hace porque ambas palabras vienen a significar, en última instancia, conjunción de materia y forma (materia «informada» por la especie o intención divina, o forma sellada, encarnada, en la materia). Esto es: las «cosas» o «naturalezas» terrenales reproducen por semejanza la esencia divina porque llevan impresa la forma sustancial (la especie o intención) que es perfecta en la mente divina (o mejor, para no humanizar a Dios, en Dios-en-cuanto-intelecto), y este sello (horma, huella, vestigio) es precisamente el que las sitúa en el orden mundanal, el que les da su lugar en la jerarquía universal. Lo que esto implica es que el mundo es una teofanía, una manifestación de Dios, conformada por la dualidad materiaforma, y que, por serlo, se constituye como orden jerárquico que reproduce el divino. Por otro lado, en las palabras de Beatriz se percibe claramente cómo esta doctrina de la participación (el mundo "participa» de la esencia divina encarnada en él) se mezcla con el causalismo aristotélico, de modo que esa forma sustancial divina que está en la "cosa» como vestigio será tanto su principio, su causa ejemplar, su origen, como su fin, su causa final, su término. Por ello, el movimiento "natural» de cada "cosa» y del universo todo será hacia esa causa final, hacia su sello divino; será, pues, un movimiento que lo aparta de la materia y lo dirige hacia su forma sustancial.

Ahora bien, la explicación de Beatriz continúa poco después con una objeción de importancia capital (Paradiso I, 127-135):

Vero è che, come forma non s'accorda molte fiate a l'intenzion de l'arte, perch' a risponder la materia è sorda, così da questo corso si diparte talor la creatura, c'ha podere di piegar, così pinta, in altra parte; e sì come veder si può cadere foco di nube, sì l'impeto primo l'atterra torto da falso piacere. 
Cierto es —indica Beatriz - que, del mismo modo que muchas veces la forma de la obra de arte (su resultado final tras la creación artística) no concuerda con la intención del artista, es decir, con la idea que previamente el artista se había hecho en su imaginación, porque la materia (la piedra, la madera con la que trabaja) no le responde, igualmente de este recorrido (es decir, del recorrido que había descrito antes: el camino hacia la causa final, el camino desde la materia hasta la forma sustancial) se desvía a veces la criatura que tiene la posibilidad de dirigirse, impelida por su «instinto» («così pinta») hacia otra parte (es decir, el ser humano, en cuyo «instinto» natural está el libre albedrío que lo puede desviar de su camino natural a Dios); y así, del mismo modo que se puede ver caer fuego de una nube (cuando lo normal, como dijo en el v. 115, es que ascienda hacia la luna), igualmente el ímpetu original (es decir, el causado por su forma sustancial, el alma racional), lo dirige hacia la tierra, hacia los bienes terrenales («l'atterra», en vez de elevarlo a Dios), torcido por el falso placer.

Nótese que en el pasaje se tocan los dos aspectos del discurso de Beatriz: en la primera parte de la comparación, la doctrina de la participación derivada del hilemorfismo aristotélico; en la segunda, la del movimiento universal hacia un fin, derivada del causalismo también aristotélico. Para comprender plenamente la primera, debemos considerar que en la mente del artista está la intención o especie (la imagen), es decir, la forma, que trata de aplicar, sin éxito, a la materia, no porque esa forma sea en sí imperfecta o el artista poco hábil, sino porque la materia "es sorda», no le responde. Lo mismo sucede, pues, con la materia del mundo moldeada por Dios: se desvía de su camino hacia la causa final no porque la forma sea imperfecta en Dios ni por culpa alguna de Dios, sino solamente porque la materia de que está hecho el mundo no se deja «informar» plenamente. O dicho de otra manera, porque si bien es cierto que el mundo es semejante a Dios, no lo es menos que el mundo es una semejanza imperfecta, esto es, que en todas las "cosas» (todas las conjunciones de materia y forma) habrá una parte semejante a Dios (la forma, especie o intención) y otra desemejante a Él (la materia). Y esta es, por supuesto, la razón por la que - como indica Beatriz en la segunda parte del pasaje- las criaturas se desvíen de su camino «natural» hacia la forma divina, o, dicho más generalmente, la razón por la que el mundo es perecedero, corrupto y pecaminoso.

Si el mundo es una manifestación de Dios, una teofanía que reproduce por semejanza, por analogía (ya sea participación, ya causalismo), las especies divinas, entonces el hombre sólo podrá conocer a Dios leyendo en el mundo sublunar su huella, sello o vestigio. No podemos describir ahora en detalle este proceso de lectura: sólo diremos que para que se produzca es necesario - por medio, primero, de un proceso de depuración imaginaria, y después de uno de análisis intelectual - desechar aquello que es desemejante a Dios, lo material, pasional, perecedero, etc., y buscar en las cosas su verdad última y su bien perfecto. Esto, sin embargo, no resulta una tarea fácil, pues justamente la clave que tematiza la contradicción de base del mundo feudal es el hecho de que la ligazón es el abismo, es decir, de que lo que une el mundo a Dios hace al 
mismo tiempo que Dios sea insondablemente distinto al mundo. $\mathrm{O}$, en otras palabras, que la semejanza sea siempre desemejante, que ambas, semejanza y desemejanza, se den sustancialmente unidas.

Resulta, creemos, bastante evidente el papel legitimador del modo de producción feudal que esta cosmovisión tenía, pero para ello no se debe olvidar que una de las consecuencias clave de la dialéctica semejanza-desemejanza es la no distinción entre naturaleza y sociedad: al ser el mundo una emanación de Dios, tan natural es un árbol (la «cosa» que lleva sellada la forma sustancial «árbol») como un siervo o un señor (las "cosas» que llevan selladas, en la sangre en este caso, las formas sustanciales «siervo» $\mathrm{y}$ «señor»). Cada «cosa», por tanto, tiene su «lugar natural», del que alejarse es pecaminoso (el destierro) y al que tender es virtuoso (la peregrinación). Como se ve en la explicación de Beatriz, el movimiento, o es un movimiento teleológico hacia el fin último (el lugar del reposo absoluto), o es síntoma de corrupción, desemejanza y pecado. $\mathrm{O}$, en otras palabras, todos los hombres son iguales a los ojos de Dios, pero para serlo deben aceptar su desigualdad natural, su lugar en el orden jerárquico universal.

Esperamos que esta somerísima descripción permita discernir el tremendo impacto que la difusión de las relaciones mercantiles ocasionó en el inconsciente ideológico sacralizado feudal: la movilidad social y el masivo abandono del lugar natural, la falta de correspondencia entre la apariencia exterior y la nobleza de sangre (nobles empobrecidos y siervos ricos), y, como consecuencia de esto último, la necesidad de refrendar el valor natural del gentilhombre por medio de virtudes públicas (es decir, ya sociales), con lo que el lugar natural empieza a convertirse en lugar social: la nobleza ya no depende sólo de la relación del hombre con su creador, sino también del hombre con los otros hombres. Tal vez sea esta realmente la gran lucha ideológica que vemos nacer en este período: la pugna por el surgimiento de una idea no sacralizada de lo «común», hoy diríamos de lo público, y, en consecuencia, el nacimiento — muy incipiente aún — de la división ideológica — necesaria para el desarrollo y la hegemonía de las relaciones mercantiles - entre un ámbito de lo privado y otro de lo público, o, en otras palabras, entre lo natural (divino) y lo social (humano), lo espiritual y lo temporal. Nótese que este principio es radicalmente inaceptable desde una perspectiva sacralizada pura, y muy difícilmente admisible desde lo que podríamos llamar la sacralización mercantil. ¿Cómo fundamentar un ámbito sagrado de lo público, de lo social, de lo autónomamente humano?: es la imposible cuadratura del círculo sobre la que Dante trabajará sistemáticamente en el Monarchia, y en muchos momentos del Convivio.

Pero, por supuesto, no era así como se percibían los avatares históricos desde dentro de la perspectiva sacralizada: desde ella, el impacto social de las relaciones mercantiles sólo puede entenderse como muestra de desorden y degradación, de que el mundo cada vez se parece menos a Dios, y una consecuencia inmediata de ello será la acentuación de los recursos sacralizados (el aumento del fervor colectivo y su demostración exterior, exaltación de 
la pobreza, etc.). Y, sin embargo, esto no basta para detener la nueva dinámica histórica. Si el mundo se ha vuelto tan sumamente desemejante a Dios que ya apenas podemos distinguir Su huella en él, poco bastará para dar el paso siguiente y empezar a preguntarse sobre el vínculo que une a Dios y el mundo, el alma al cuerpo, el significado al texto, etc. Se comenzará entonces a replantear, a repensar, a problematizar la idea misma de encarnación, de analogía, de semejanza, la unión entre lo sublunar y lo supralunar, y, en consecuencia, las bases mismas de la legitimación del poder sacralizado. De hecho, si lo pensamos detenidamente, todas las grandes cuestiones de finales del siglo XIII y principios del XIV, desde la polémica averroísta hasta el voluntarismo y el nominalismo, pasando, por supuesto, por la cuestión del amor y de la poesía en el estilnovismo, no son otra cosa que modos de revisar cómo se ligan el mundo sublunar y el supralunar y cuál es su abismo, hasta que, con Boccaccio y Petrarca, se alumbre un modo distinto de entender las relaciones cuerpoalma, cielo-tierra, etc., y se produzca así la coupure ideológica necesaria para el desarrollo del mercantilismo. ${ }^{3}$

Pero hasta ese momento, el intelectual de la sociedad sacralizada mercantil sólo puede tratar de paliar los estragos de la crisis general de lectura. A nuestro entender, ello es lo que fuerza a Dante a una profunda reelaboración, e incluso cuestionamiento, de las nociones básicas del entramado ideológico feudal, que aunque él, inconsciente y difusamente — nos atrevemos a suponerpueda sentir desajustado y en incipiente ruina, aún considera válido, en líneas generales, y fuente directa de verdad. Por ello, desde el principio mismo del Convivio trata de marcar distancias tanto con el intelectual clerical feudal como con el planteamiento utilitarista de los intelectuales burgueses del Comune: él hablará para los que tienen nobleza de alma, "principi, baroni, cavalieri e molt'altra nobile gente, non solamente maschi ma femmine» (Conv. I Ix 5) ${ }^{4}$ - es decir, para la aristocracia mercantil que trata, infructuosamente, de instaurar una nueva legitimidad civil sacralizada-, y lo hará con un doble fin: «inducir a los hombres a la ciencia y a la virtud» (Conv. I xi 7), es decir, encaminarlos, por un lado, por la senda de la sabiduría que les permita, leyendo adecuadamente, alzarse del mundo sublunar al supralunar (ciencia), y, por otro lado - pero son los dos lados de una misma moneda —, por la vía de las buenas obras sociales ciudadanas y cortesanas (virtud). Como explica Vasoli, por una parte, "permitir la plena actuación de las "potencialidades" específicas de la mente humana", por otra, "ayudar a quien vive y actúa en la "ciudad" a obrar para el advenimiento de la paz y de la armonía civil».5 Para nosotros,

3. En realidad, la nueva relación no nace con los textos de Boccaccio y Petrarca, sino que esos textos tematizan una relación que ya existía en el inconsciente ideológico de clase: de ahí la metáfora del alumbramiento.

4. Citamos a partir de la edición de Franca Brambilla Ageno (Dante Alighieri, Convivio, a cura di Franca Brambilla Ageno, Firenze: Casa editrice Le Lettere, 1995).

5. Cesare Vasoli, «Intoduzione» en Dante Alighieri, Convivio, Milano-Napoli: Ricciardi, p. XI-XII. 
esta unión entre conocimiento sagrado y acción civil es una de las claves fundamentales del Convivio, en el que la función social del saber, la concepción de la filosofía como actividad social, e incluso política, es inseparable - por extraño que pueda parecernos setecientos años más tarde- de su concepción sacralizada como expresión de la sabiduría eterna. El Convivio se nos aparece, así, como un auténtico programa de "sacralización civil» en el que, aún reproduciéndose la dualidad sacralizada entre mundo sublunar y mundo supralunar, se trata de imprimir a ambos de nuevos "contenidos» que acabarán de identificar lo supralunar, el alma, con el valor individual (la nobleza de alma) y lo sublunar con sus virtudes civiles como encarnación de ese valor individual natural. ${ }^{6}$

Así, pues, no es de extrañar que, si tratamos de lograr una visión general del conjunto de temas que componen el Convivio, distingamos dos grandes constelaciones de asuntos o preocupaciones: por un lado, los que afectan al vínculo entre el mundo supralunar y el mundo sublunar, lo cual a su vez se dividirá en otros dos grandes bloques, según se estudie la relación entre ambos de arriba a abajo, como problema de la generación o creación, o de abajo a arriba, como problema del conocimiento; por otro lado, los que atañen a la legitimación de una nueva organización social. Ambas constelaciones convergen en la cuestión del conocimiento: la sabiduría está en el quicio abismal donde se unen mundo y Dios, y es, al tiempo, la esencia de la nobleza del alma base de la nueva sociedad civil sacralizada. Por ello, no sorprende que, como señala Vasoli, ${ }^{7}$ nos encontramos en el Convivio ante una filosofía humana fundamento del orden civil que es, al tiempo, la verdad eterna fundamento del orden universal.

Repasemos, una vez explicada nuestra idea central, algunos de los temas aludidos, sin pretensiones, por supuesto, de exhaustividad.

Los temas que tratan de reafirmar —o restablecer- el dañado vínculo entre Cielo y Tierra - y su correspondiente abismo- , ya sea de arriba a abajo como problema de la generación-creación, ya de abajo a arriba como problema del conocimiento, protagonizan específicamente los tratados II y III del libro, y en ambos recorridos -insistimos: estrechamente imbricados - se puede apreciar un crescendo en intensidad e importancia, pero también en el grado de contradicción interna de los argumentos, que a medida que se van desarrollando van llevando a Dante a un callejón sin salida. Separando de manera artificial los asuntos, pero sin olvidar que en esta vivisección se pierden, aparte de los imprescindibles matices, las interrelaciones - o más bien, las intersecciones - entre ellos, podemos decir que el problema de la generacióncreación tiene el siguiente desarrollo:

6. Recuérdese, por ejemplo, cuando Dante justifica su libro desde un punto de vista personal (Conv. I II-IV) también sitúa la justificación en dos niveles: uno individual, defenderse de la calumnia como Boecio, otro colectivo, enseñar a los demás la vía de la felicidad como San Agustín.

7. Cesare Vasoli, op. cit., p. LXXIII. 
1) Inciso sobre cosmología celeste y angeología (Conv. I III-v) > 2) Excursus sobre la inmortalidad del alma (Conv. II viII) > Correspondencias entre los cielos y las ciencias (Conv. II XIII-XIV) > 4) Fundamentación del deseo amoroso en la participación del mundo sublunar en la naturaleza divina: el amor como principio, deseo y fuerza presente en todos los grados del ser (Conv. III II-III) > 5) La Tierra como centro del universo (Conv. III v) > 6) Recorrido por la causalidad general del universo como fundamento del orden jerárquico (Conv. III vi) > 7) La dama como semejanza perfectísima, naturaleza angélica, previo recorrido por los grados del ser participado (Conv. III vII-VIII).

Por su parte, el problema del conocimiento ofrece el siguiente desarrollo:

1) La cuestión de la alegoría (Conv. II I) > 2) Lucha intelectual entre el amor por Beatriz y el amor por la nueva dama gentil (Conv. II II, VI, IX) > 3) Inmersión en el amor-estudio filosófico (Conv. II XII, Xv) > 4) El problema de la doble inefabilidad (Conv. III Iv) > 5) Relaciones con la dama-filosofía (Conv. III IX-X) > 6) La cuestión averroísta (Conv. III XI-XV).

La imbricación de ambas constelaciones temáticas, creación divina y conocimiento humano, se puede apreciar bien, por ejemplo, en la necesidad que tiene Dante de comenzar un libro cuyo tema central, al menos en los tratados II y III, es el del conocimiento con un largo inciso sobre cosmología celeste y angeología, que, tras la declaración de intenciones introductoria del tratado I y del primer capítulo de tratado II, abre el contenido del libro propiamente dicho. En este excursus, Dante «no sólo toca cuestiones particulares que conciernen a la naturaleza universal de los cielos y de sus influencias, sino que también trata del carácter y función de las Inteligencias separadas en el orden cósmico, de su creación y de su número», ${ }^{8}$ es decir, de todos aquellos elementos que sirven para establecer, de arriba abajo, el vínculo entre el mundo supralunar y el mundo sublunar.

Ahora bien, lo que más nos interesa destacar — dado que no podemos repasar tema a tema- es cómo en el tratado III la ligazón por participación y causalismo del mundo sublunar con el supralunar, que lo ordena jerárquicamente, se convierte, por un lado, en el vínculo que permite el conocimiento haciendo de la dama gentil la naturaleza más semejante a Dios que el hombre puede encontrar, pero, al mismo tiempo, en el abismo que impide ese conocimiento, sometiendo al intelecto humano a las limitaciones de la doble inefabilidad. El círculo — vicioso o virtuoso, según se mire- se puede delinear de la siguiente manera, aun a riesgo de dotar al texto de una coherencia que, como luego veremos, realmente no posee:

El universo es un orden jerárquico, regido, en cuanto que orden intelectual, por la ley de la causalidad ("[nel]l'ordine intellettuale de l'universo si sale e discende per gradi continui de la infima forma a l'altissima [e da l'altissima] a la infima», Conv. III viı 6), y, en cuanto que orden teleológico, por la ley de la 
participación amorosa (Conv. III III). La ley de la causalidad es, por supuesto, la que posibilita el conocimiento, en cuanto que permite alzarse de los efectos a las causas progresivamente, hasta alcanzar la causa primera. Pero este ascenso no se produciría si el ser humano no desease conocer, si el hombre no tuviese, como ser racional, un amor natural a la verdad y a la virtud (Conv. III III 11). Este amor, que habla en la mente, es decir, en el alma racional, como primer impulso hacia la verdad y la virtud, viene despertado por la dama, en cuanto que esta es - y este pasaje es clave- «l'essemplo intenzionale che della umana essenzia è ne la divina mente e, per quella, in tutte l'altre» (Conv. III vi 6). Ejemplo intencional, esto es: especie divina ejemplar, forma inteligible pura. De la humana esencia, es decir: de la propia alma racional humana. Imagen de la mente humana en la propia mente humana por participación de esta en la mente divina. Imagen del alma en el alma. Por ello, sólo se puede tener experiencia de ella «in quelle operazioni che sono proprie dell'anima razionale» (Conv. III vII 8), el hablar y los gestos, y, como indicábamos, esta experiencia-percepción (en la imaginación) de la dama "genera nella mente di chi l'ode uno pensiero d'amore, lo quale io chiamo spirito celestiale, però che là su è lo suo principio e di là su viene la sua sentenza» (Conv. VIII viI 12). Así, impulsado por este "pensiero d'amore» se inicia el conocimiento entendido como conocimiento de las causas, e, indisolublemente, como "unimento spirituale» con la cosa amada (Conv. III II 3). Ahora bien, iniciado este camino, se topa con el impedimento de la doble inefabilidad: la de la imaginación para servirle imágenes al intelecto, y la del lenguaje para representar esas imágenes intelectuales (es decir, con "la loro sentenza», llenas de significado, alegóricas):

Onde, acciò che questa natura si chiama mente, come di sopra è mostrato, dissi 'Amore ragionare ne la mente', per dare ad intendere che questo amore era quello che in quella nobilissima natura nasce, cioè di veritade e di vertute, e per ischiudere ogni falsa oppinione da me, per la quale fosse sospicato lo mio amore essere per sensibile dilettazione. Dico poi «disiosamente», a dare ad intendere la sua continuanza e lo suo fervore. E dico: move sovente cose che fanno disviare lo 'ntelletto'. E veramente dico; però che li miei pensieri, di costei ragionando, molte fiate voleano cose conchiudere di lei, che io non le potea intendere, e smarrivami, sì che quasi parea di fuori alienato: come chi guarda col viso per una retta linea, prima vede le cose prossime chiaramente; poi, procedendo, meno le vede chiare; poi, più oltre, dubita; poi, massimamente oltre procedendo, lo viso disgiunto nulla vede.

E quest'è l'una ineffabilitade di quello che io per tema ho preso; e consequentemente narro l'altra, quando dico: «Lo suo parlan». E dico che li miei pensieri - che sono parlare d'Amore - 'sonan sì dolci' che la mia anima, cioè lo mio affetto, arde di potere ciò colla lingua narrare; e perché dire nol posso, dico che l'anima se ne lamenta dicendo:

[Oh me] lassa! Chio non son possente.

E questa è l'altra ineffabilitade; cioè che la lingua non è di quello che lo 'ntelletto vede compiutamente seguace. E dico "l'anima ch'ascolta e che lo sente»: 'ascoltare' quanto a le parole, e 'sentire' quanto a la dolcezza del suono (Convivio III, III, 12-15). 
Obsérvese que si son el habla y los gestos de la dama los que mueven al alma racional humana (Conv. III viI 8-17), justamente lo que falla después en el hombre es su capacidad verbal y su capacidad imaginaria (la que recoge los gestos). Pero, sobre todo, nótese que es precisamente el mismo exceso de nobleza - de semejanza - de la dama con respecto al intelecto humano que hace nacer el deseo de conocer el que impide - al modo cavalcantiano- el aplacamiento de ese deseo (Conv. III rv): la ligazón es abismo — y cuanto más estrecho el vínculo, más infranqueable el abismo-, contradicción de base del inconsciente ideológico sacralizado feudal que en esta circunstancia histórica emerge a la luz provocando interesantísimas contorsiones intelectuales. Dante se ha dado de bruces con la cuestión averroísta, contra la que se enfrenta denodadamente en los capítulos XI a XV de este tratado tercero: ¿cómo conjugar la infinitud del deseo humano por conocer, por unirse a Dios, con las limitaciones materiales del intelecto? Dante afirma, como principio, que la verdadera felicidad sólo se alcanza en la contemplación de la verdad, y se extiende entonces en una celebración de la suprema perfección de la filosofía-sabiduría, y en una exaltación de la virtud especulativa y de la beatitud que de ella deriva. Ahora bien, una cosa es la «divina filosofía» que está en la esencia divina, y otra la participación, "por modo menor», que de esa filosofía tienen las «inteligencias», para las que la filosofía puede ser sólo una "druda» (amiga) en cuya belleza se aplaca el deseo. La filosofía es, por tanto, imperfecta y perfecta al tiempo, pues, aunque permita despreciar los bienes inferiores que no producen verdadera felicidad, tampoco lleva completamente a esta, ya que el intelecto sólo puede dedicarse a ella de modo discontinuo y parcial. Y sin embargo, lo que no es discontinuo y parcial — cuando una persona adquiere el hábito de la filosofía y se convierte en filósofo, es decir, en su amante- es el amor que la filosofía genera. Así pues, el hombre se enfrenta a la contradicción insoportable entre un deseo natural de Verdad y Felicidad, y la imposibilidad de saciarlo en esta vida, lo cual contraviene el principio averroísta, que Dante acepta, de que todo deseo natural debe poder saciarse naturalmente (una hermosa variación de la idea de que, en última instancia y a pesar de las apariencias, el mundo está bien hecho). Ante esta contradicción, Dante — tras un durísimo forcejeo mentaltermina ofreciendo una solución que supone realmente una, aunque sea momentánea, derrota intelectual: niega que el deseo de conocer a Dios y otras cosas superiores a nuestra naturaleza sea natural en el hombre:

Veramente può qui alcuno forte dubitare come ciò sia, che la sapienza possa fare l'uomo beato, non potendo a lui perfettamente certe cose mostrare; con ciò sia cosa che 'l naturale desiderio sia [nel]l'uomo di sapere, e sanza compiere lo desiderio beato essere non possa.

A ciò si può chiaramente rispondere che lo desiderio naturale in ciascuna cosa è misurato secondo la possibilitade de la cosa desiderante: altrimenti anderebbe in contrario di se medesimo, che impossibile è; e la Natura l'averebbe fatto indarno, che è anche impossibile.

In contrario anderebbe: ché, desiderando la sua perfezione, desiderrebbe la sua imperfezione; imperò che desiderrebbe sé sempre desiderare e non 
compiere mai suo desiderio (e in questo errore cade l'avaro maladetto, e non s'acorge che desidera sé sempre desiderare, andando dietro al numero impossibile a giugnere). Averebbe[lo] anco la Natura fatto indarno, però che non sarebbe ad alcuno fine ordinato. E però l'umano dediderio è misurato in questa vita a quella scienza che qui avere si può, e quello punto non passa se non per errore, lo quale è di fuori di naturale intenzione. $\mathrm{E}$ così è misurato nella natura angelica e terminato, in quanto, in quella sapienza che la natura di ciascuno può apprendere. E questa è la ragione per che li Santi non hanno tra loro invidia, però che ciascuno aggiugne lo fine del suo desiderio, lo quale desiderio è colla bontà della natura de la bontà misurato. Onde, con ciò sia cosa che conoscere di Dio, e di certe altre cose, quello esso è, non sia possibile alla nostra natura, quello da noi naturalmente non è desiderato di sapere. E per questo è la dubitazione soluta (Conv. III xv 7-10).

La derrota no está tanto en el hecho de que Dante se vea forzado a realizar un razonamiento aparentemente heterodoxo con respecto al pensamiento teológico y más cercano al de los magistri in artibus de París (si todo deseo natural debe ser satisfecho, y el deseo de conocer a Dios no puede serlo, entonces tal deseo no es natural), sino sobre todo en que con tal razonamiento acepta la separación - que van imponiendo las relaciones mercantilesentre dos naturalezas, dos deseos, dos conocimientos y dos felicidades, aceptando así la ruptura del vínculo que pretendía restablecer desde el comienzo de su actividad poético-intelectual.

Como ha sido generalmente observado, el tratado cuarto se diferencia de los anteriores pues trata de un tema, digamos, social: el de la nobleza de alma frente a la nobleza de sangre. Sin embargo, como pone en evidencia Vasoli, este asunto está estrechamente ligado al de la generación, por un lado, pues es Dios quien confiere dicha nobleza anímica a las personas individuales y no a las estirpes, y, por otro lado, al del conocimiento, pues sólo el alma noble puede emprender la vía de las virtudes intelectuales. A nuestro entender, lo que muestra este tratado cuarto de manera meridianamente clara es que el eje mundo supralunar-mundo sublunar se ve "contaminado" por el eje, generado ya desde el modo de producción mercantil, privado-público. En líneas generales, digamos que lo supralunar se vendrá a identificar con el «valor» individual, es decir, lo intelectual (o amoroso, que es exactamente lo mismo), mientras que lo sublunar se identificará con la virtud pública, colectiva (lo moral): la práctica política, la retórica, etc., por supuesto, con las contradicciones y

9. Sobre el asunto, basta remitir al documentadísimo y minucioso libro de Paolo Falzone, Desiderio della scienza e desiderio di Dio nel Convivio di Dante, Bologna: Il Mulino, 2010. Por otro lado, Carlos López Cortezo ha mostrado en un reciente trabajo que esta afirmación es mucho menos heterodoxa de lo que podría parecer (Carlos López Cortezo, «Il sesso della Filosofia. A proposito di 'Voi che intendendo il terzo ciel movete'», en Grupo Tenzone, Voi che 'ntendendo il terzo ciel movete, edición de Natascia Tonelli, Madrid: Departamento de Filología Italiana (UCM)-Asociación Complutense de Dantología, 2011, p. 133-156. 
matices imprescindibles en cada caso. ${ }^{10}$ Ahora bien, repárese en que a esta "contaminación» subyace una contradicción de fondo insoportable, pues supone aceptar inconscientemente la distinción entre lo social y lo natural, o, en otras palabras, minar por la base cualquier legitimación sacralizada del poder social: ¿cómo eliminar, entonces, esta legitimación, cuando aún no se puede aducir una legitimación plenamente civil, independientemente de la generación divina sellada en la sangre? Veamos someramente cómo lo intenta Dante.

Dante parte, para rechazarla, de la definición de nobleza o gentilezza atribuida por la fama a Federico II de Suecia, al que considera último y legítimo «emperador de los Romanos», según la cual la nobleza consiste en antigua riqueza y bellas costumbres, definición en la que muchos habían suprimido la segunda parte. Ahora bien, rebatir una opinión imperial obliga a Dante a abordar preliminarmente el propio concepto de autoridad imperial: no repasaremos ahora esta larga digresión porque, como ya mostró hace tiempo Bruno Nardi, es el origen y meollo ideológico del Monarchia: sólo señalaremos algo a nuestro entender importantísimo, como muestra de cómo un inconsciente mercantilista aún larvado va poco a poco imponiendo su principio básico: la relación entre individuo y sociedad, el primero como incipiente fundamento de la segunda, aunque ambas sean aún entidades sacralizadas. Así, el tema de la autoridad imperial en cuanto autoridad civil sacralizada va estrechamente ligado al de la nobleza de alma en cuanto individualidad civil sacralizada, es decir, la reflexión sobre la base de la sociedad va unida a la reflexión sobre la base de la individualidad, de modo que, a la postre, las dos fundamentaciones son idénticas: es el poder de Dios el que, directamente — sin mediar la naturaleza del linaje- pone en el alma la semilla de la nobleza y elige al soberano universal. La voluntad directa de Dios es, pues, tanto el fundamento de la sociedad como el de la individualidad. A este respecto, creemos que han sido poco exploradas las coincidencias ideológicas entre Dante y el voluntarismo scottista-occamista. A nuestro entender, existe una que genera y condiciona ambas construcciones ideológicas desde su base: la necesidad de crear una nueva legitimidad, que de nuevo ligue la Tierra al cielo, fundamentando así una nueva autoridad civil en principios sacralizados, ahora que la nobleza de sangre, la mera encarnación del cielo en la Tierra, estaba echada a perder por el impacto continuado de las relaciones mercantiles.

Además de rebatir la opinión imperial, Dante se ve también en la necesidad de lidiar con una afirmación aristotélica según la cual la opinión de muchos debe contener algún grado de verdad (consideración ya burguesa de la opinión pública). Ello lo lleva a enfrentarse con el concepto mismo de «filosófica autoridad», que se complementa con la Imperial de modo que ésta sin aquélla es peligrosa y aquélla sin ésta débil. Lo que Dante realiza en estas páginas es un movimiento intelectual de gran importancia, pues, tras toda la fundamenta-

10. Esta contradicción existe ya en la lógica caballeresca feudal, en la que el caballero debe refrendar su nobleza de sangre con obras y virtudes cortesanas, es decir, sociales. 
ción del saber como participación de la sabiduría eterna realizada en los tratados II y III, ahora liga ese saber a lo que podemos llamar la acción social, la consecución de la felicidad terrena que sólo puede lograrse en comunidad y por medio de la razón. Así, tras sentar firmemente las bases de su «discurso social sacralizado", a Dante le resulta relativamente fácil refutar la opinión común que fundamenta la nobleza en el linaje y en la riqueza. La primera noción apenas tiene ya sentido en el nuevo mundo comunal, por lo que basta con mirar alrededor para ver cómo de padres nobles nacen hijos viles, y basta con pensar un poco para percatarse de la inconsistencia de la idea de que el hijo de un hombre «villano» no pueda nunca convertirse en noble o gentil, lo que haría que, dado que Adán es el primer padre de todos, «seamos todos gentiles o bien todos villanos».

Una vez refutada la fundamentación sacralizada pura de la noción de nobleza, Dante debe proponer una noción alternativa de identidad, basada en el individuo aunque sin romper con la sacralización, y debe hacer residir en él la nueva legitimación social que la sociedad feudal-mercantil, y la correspondiente aristocracia mercantil, necesita.

En el primer caso, la reflexión dantesca es muestra, como apuntábamos, de un movimiento inconsciente similar al que genera el voluntarismo de un Duns Scoto o el nominalismo de un Guillermo de Occam (teórico también de la autoridad imperial, desde presupuestos no muy alejados de los de Dante): si el mundo es ya tan desemejante a Dios que parece incluso hacer dudoso que esté ligado formalmente o sustancialmente a Él —idea que Occam plantea, pero no Dante-, y si, al mismo tiempo, las relaciones mercantiles no alcanzarán hasta muchos siglos después la suficiente autonomía como para superar la idea de sacralización, entonces es necesario imaginar una fundamentación de la identidad que, sin basarse en el vínculo formal-sustancial del mundo con Dios (en el linaje, pues), remita, en última instancia, a la divinidad. De ahí la idea scotiana y occamiana de que Dios rige el mundo, no a través de la naturaleza, sino por un acto de su voluntad; y la idea dantesca de que la nobleza es una gracia, un don (una semilla), que Dios coloca no "in ischiatta» (en la estirpe) sino en el alma de cada individuo. Ahora bien, tras esta definición central, Dante decide tratar de cómo ese «semen de la felicidad» que es la nobleza desciende en el alma primero por «modo natural» y luego por «modo divino o espiritual», con lo que, de nuevo, la separación entre los dos mundos, la doble vía filosófica y teológica, parece imponérsele irremediablemente. Y en este nuevo forcejeo mental contra las implicaciones desacralizadoras de su pensamiento — dolorosa lucha mental contra sí mismo - afloran todas las contradicciones con las que se mide Dante: pues si, por un lado, la vía natural sirve para probar el vínculo del alma con Dios a través de la acción de las Inteligencias motrices —que infunden el «intelecto posible» (intelecto en el que los inteligibles están en potencia) de manera más o menos perfecta según la disposición, en el momento de la generación, de los cielos y del alma que lo recibe-; por otro lado, la vía teológica nos muestra — a pesar de afirmaciones explícitas en contra- a un Dios que concede la nobleza según el alma esté 
preparada, por la naturaleza, para recibirla, esto es, un Dios cuya voluntad está previamente limitada, condicionada por la naturaleza. Como se ve, por mucho que se luche teóricamente contra ella, la inconsciente necesidad de dotar de autonomía a la naturaleza, separándola sustancialmente de Dios, parece imponerse en nociones tales como la de "disposición» (que no se hace depender de Dios), por lo que la fundamentación dantesca del alma noble se convierte en paso previo imprescindible para la ideología del alma humanista en la que la fundamentación de la nobleza depende exclusivamente de la expresividad de una naturaleza impregnada de alma bella.

El segundo aspecto que enunciamos - la relación entre el orden civil y la nobleza de alma - parte justamente de la concepción de la nobleza como semilla divina, pues, como toda simiente, la nobleza debe ser cultivada. En este sentido, la nobleza se presenta desde el comienzo de la reflexión como el origen de todas la virtudes, tanto de las morales o prácticas como de las intelectuales, y, en consecuencia, como la fuente de la felicidad humana. Esta felicidad se alcanza sobre todo mediante la especulación intelectual, por lo que nobleza y filosofía están siempre unidas por un mutuo amor en el que el círculo virtuoso se cierra: la nobleza se infunde de arriba abajo y se desarrolla, como participación en la sabiduría divina, de abajo arriba, lo que lleva al hombre — guiado por esta nueva clase noble y amante de la sabiduría - a la felicidad civil y personal.

Esta circularidad sólo puede cerrarse completamente si el hombre se deja impulsar por un deseo que le permita secuenciar correctamente el camino ascensional del conocimiento, es decir, que le conceda, en el momento de su saciamiento, el estado de reposo y plenitud fuera del tiempo que, según Aristóteles (Ética a Nicómaco 1174 a, b) y Tomás de Aquino (Comentario a la Ética 1439-1443), caracteriza al auténtico deleite. En los asombrosos capítulos XII y XIII del tratado IV, Dante contrapone el deseo de riqueza al deseo de ciencia: mientras que el primero siempre crece, pero no perfecciona, pues produce un deleite siempre ansioso, que lleva inscrito en su propio acto la promesa, y por ello la necesidad, de un deleite mayor, y es, de este modo, intrínsecamente incompleto pues fuerza al que lo padece a pasar sin orden de un objeto a otro, del segundo, el deseo de ciencia, no se puede decir propiamente que crezca, sino que se dilata (Conv. IV XIII 1), con lo que Dante está recogiendo un concepto que Tomás de Aquino explica en su Suma de teología (I-II, q. 33, a. 1) para indicar que el deseo de ciencia no es uno, sino cualitativamente diverso en cada uno de sus pasos, y, por ello, al alcanzar uno de ellos, sí podemos experimentar el descanso y la perfección de un deleite auténtico. A nuestro entender, Dante intuye, en esta contraposición, el peligro que supone el nacimiento histórico de un deseo que se fija en fetiches sustitutorios (en mercancías), y que, por ello, impide el auténtico deleite — con su momento de reposo, de pausa reflexiva - que da el camino del conocimiento que reengancha al hombre con el orden universal.

Somos conscientes de que nuestra lectura —ordenando los temas, estableciendo progresiones... - dota al texto del Convivio de una coherencia de la 
cual carece en su génesis constructiva consciente. Por ello, querríamos terminar señalando el hecho de que el Convivio es un texto, no sólo inacabado, sino también quebrado, sin equilibrio, desmesurado en algunos momentos: no una perfecta construcción sino la consecuencia de una búsqueda a nuestro parecer desgarrada e infructuosa, vivida intensamente desde el punto de vista personal. Como es sabido, la identificación de las fuentes doctrinales de las ideas dantescas es uno de los asuntos que más enconadamente ha enfrentado a unos y otros críticos a lo largo del siglo xx, y así, si en los años 20 el padre Busnelli y el padre Mandonnet trataban por todos los medios de probar el tomismo de Dante, eran inmediatamente respondidos por filósofos como Bruno Nardi y Etienne Gilson, quienes resaltaban ante todo las raíces averroístas del pensamiento dantesco, para, más recientemente, venirse a dar también mucha relevancia a los elementos platónico-agustinianos, que se habrían fundido con los averroístas en la obra de Alberto Magno, de capital influencia en Dante. Toda esta larga tradición de valiosísimos estudios ha llevado asimismo a la convicción muy difundida del carácter ecléctico del pensamiento dantesco, ante la cual conviene subrayar, como hace Vasoli, ${ }^{11}$ el componente que este tiene, más allá del eclecticismo, de reelaboración arriesgada, conflictiva, dubitativa en muchos casos, llevada a cabo desde una actitud filosófica de «búsqueda constantemente abierta y nunca completamente agotada sobre "materiales" que la cultura a la que pertenecía había elaborado»: ${ }^{12}$ conflictividad, riesgo y dudas que, a nuestro entender, son consecuencia, no tanto, como quiere Vasoli, de la libertad y energías de un espíritu sin prejuicios y esencialmente comprometido - imagen demasiado similar a la del intelectual burgués liberal de postguerra-, cuanto de la imposibilidad histórica de romper con la sacralización y, al tiempo, de la necesidad de utilizar un entramado de ideas y presupuestos sacralizados para explicar y legitimar un mundo en transformación: el pensamiento, pues, de un momento de aguda crisis ideológica, cuando las ideas que explican-legitiman hegemónicamente el mundo ya no sirven, pero aún no se han impuesto otras que lo hagan.

Por eso el pensamiento de Dante busca intensamente la coherencia y resulta, sin embargo, profundamente contradictorio, quebrado, incluso a menudo terminológicamente impreciso y ambiguo (y de todo ello deriva, sin duda, su riqueza, su capacidad de sugestión); por eso, Dante siente fuertemente la necesidad de partir de los "principios» y tratar de las cuestiones «básicas». Dante va ahondando en la contradicción de partida al intentar resolverla, y por eso el Convivio se convierte en una obra clave en su trayectoria. Por un lado, se liga estrechamente a la Vita nuova, con la afirmación expresa (Conv. I i 16) de que ambas obras tratan de lo mismo —el problema del conocimiento, más su complementario, el de la ligazón mundo-Dios-, aunque de manera distinta: la juvenil, en modo ardiente y apasionado; la más madura, en modo templado

11. Cesare VAsoli, op. cit., p. LXXVII-LXXVIII.

12. Ibid., p. LXXVIII. 
y viril, o, en otras palabras, añadiendo esta a aquella un ejercicio racional de orden y análisis que sistematiza los mismos contenidos, la misma problemática general, y que templa y modera las imágenes por las que esos contenidos se expresan, uniéndolas en un modo más coherente y lógico con ellos. Por otro lado, esta sistemación y este análisis, no sólo de los contenidos, sino también del modo de ligar la letra y la alegoría es labor previa imprescindible tanto para hallar el justo medio expresivo de la Commedia, como para resolver la cuestión del conocimiento que permitirá el viaje del alma humana $-\mathrm{y}$ de la imaginación a ella abismalmente unida - desde la selva oscura de la irracionalidad y el pecado hasta el Empíreo de la inteligencia pura y la eterna felicidad. Y así, el Convivio es, a pesar de la derrota intelectual en que desemboca $-\mathrm{O}$ tal vez gracias a ella-, la bisagra en la que se produce el giro necesario para, si no escalar el alto monte de la cuestión del conocimiento - y de las contradicciones inconscientes que la subyacen-, sí al menos emprender el largo camino que lo rodee y busque una subida más llevadera y soportable. 